\title{
Yield quantitative trait loci from wild tomato are predominately expressed by the shoot
}

\author{
Amit Gur • Yaniv Semel · Sonia Osorio • Michael Friedmann · Saleh Seekh • \\ Bilal Ghareeb · Ayed Mohammad • Tzili Pleban • Gabi Gera • Alisdair R. Fernie • \\ Dani Zamir
}

Received: 12 March 2010/Accepted: 9 September 2010/Published online: 26 September 2010

(C) The Author(s) 2010. This article is published with open access at Springerlink.com

\begin{abstract}
Plant yield is the integrated outcome of processes taking place above and below ground. To explore genetic, environmental and developmental aspects of fruit yield in tomato, we phenotyped an introgression line (IL) population derived from a cross between the cultivated tomato (Solanum lycopersicum) and a wild species (Solanum pennellii). Both homozygous and heterozygous ILs were grown in irrigated and non-irrigated fields and evaluated for six yield components. Thirteen lines displayed transgressive segregation that increased agronomic yield
\end{abstract}

Communicated by M. Havey.

Electronic supplementary material The online version of this article (doi:10.1007/s00122-010-1456-9) contains supplementary material, which is available to authorized users.

A. Gur · Y. Semel · T. Pleban · D. Zamir

The Institute of Plant Sciences and Genetics in Agriculture,

Faculty of Agriculture, The Hebrew University of Jerusalem,

P.O. Box 12, 76100 Rehovot, Israel

S. Osorio · A. R. Fernie $(\bowtie)$

Max-Planck-Institute of Molecular Plant Physiology,

Am Mühlenberg 1, 14476 Potsdam-Golm, Germany

e-mail: fernie@mpimp-golm.mpg.de

M. Friedmann

Department of Genetics, Institute of Field Crops,

The Volcani Center, A.R.O, P.O. Box 6, 50250 Bet Dagan, Israel

S. Seekh · A. Mohammad

Hebron University, P.O. Box 40, Hebron, Palestine

B. Ghareeb

Biology and Biotechnology Department,

Arab-American University, P.O. Box 240, Jenin, Palestine

G. Gera

Akko Experimental Station, 25212 Western Galilee, Israel consistently over 2 years and defined at least 11 independent yield-improving QTL. To determine if these QTL were expressed in the shoots or the roots of the plants, we conducted field trials of reciprocally grafted ILs; out of 13 lines with an effect on yield, 10 QTL were active in the shoot and only IL8-3 showed a consistent root effect. To further examine this unusual case, we evaluated the metabolic profiles of fruits from both the homo- and heterozygous lines for IL8-3 and compared these to those obtained from the fruit of their equivalent genotypes in the root effect population. We observed that several of these metabolic QTL, like the yield QTL, were root determined; however, further studies will be required to delineate the exact mechanism mediating this effect in this specific line. The results presented here suggest that genetic variation for root traits, in comparison to that present in the shoot, represents only a minor component in the determination of tomato fruit yield.

\section{Introduction}

Since the beginning of plant domestication, man has invested efforts at improving crop productivity, by agronomic and genetic means. This process is still taking place; however, there is a real need to find new approaches to secure food availability (Hoisington et al. 1999; Rosegrant and Cline 2003; Peng et al. 2004; Ash et al. 2010). Scientists and breeders have been aiming to improve plant adaptation to abiotic stress factors, so that they can be grown in areas that are presently not in agricultural use (Heaton et al. 2008; Fedoroff et al. 2010).

An important step in the general understanding of yield, but specifically under conditions of drought, is to characterize the physiological basis of the variation and to 
determine whether the site of expression of the QTL is in shoots and/or in roots. This can be done by physiological measurements, which are usually performed on the plant canopy; however, when tested in parallel to yield-related traits, such parameters were generally independent of yield values under drought conditions (Mansur et al. 1993; Teulat et al. 1998; Specht et al. 2001). A grafting strategy can assist in determining whether specific yield QTL are caused by shoot or root traits. Shoot traits are easy to measure, whereas the information available on the genetic control of root traits in the field and their relationship with yield is limited due to the fact that such measurements are complicated and until recently (Janhnke et al. 2009) have been exclusively destructive (Tuberosa et al. 2002). Even now, such techniques remain prohibitively expensive and are not readily adapted to field evaluation. For this reason, although QTL for root characteristics have been analyzed in several crop species including rice (Champoux et al. 1995; Ray et al. 1996; Yadav et al. 1997; Swarbrick et al. 2008), faba bean (Diaz-Ruiz et al. 2010) and maize (Lebreton et al. 1995), they were not characterized under field conditions and thus could not be associated with yield. Some groups have attempted to uncover such an association (Guingo et al. 1998; Tuberosa et al. 2002); however, the approach used was somewhat limited since they measured root characteristics under greenhouse conditions (hydroponics on the latter), while yield or biomass traits were measured in the field. Although much work has recently been carried out on Arabidopsis, most of this has focused on environmental response of the roots themselves to either toxic metals, nutrients or pathogens (see for example Hoekenga et al. 2006; Svistoonoff et al. 2007). While biomass has been measured in several studies, the translatability of this data to crop species has by no means been proven.

Yield-associated QTL were previously identified and mapped (Eshed and Zamir 1995), but no attention was paid to the association of these QTL to root or shoot traits. In the present study, we used grafting to directly associate yield to root or shoot traits. Grafting is a well-established technique in many plants, including tomato, and is used for both physiological and genetic characterization of root and shoot interactions (Estañ et al. 2005; Van der Merwe et al. 2009). Here, we utilized natural variation derived from the green-fruited wild tomato species Solanum pennellii to investigate the genetic basis of yield, under optimal and drought-stress conditions. An introgression line (IL) population composed of 75 lines, each including a single introgressed genomic region from $S$. pennellii, such that between lines there was complete representation of the wild-species genome (Eshed and Zamir 1995; Pan et al. 2000), was grown alongside a second population that was heterozygous for each introgression (Semel et al. 2007).
We show here that whole-genome QTL mapping followed by reciprocal grafting of selected lines can lead to the identification and characterization of wild species shoot and root QTL, which improve agricultural yield and provide a preliminary characterization into metabolic factors that may be responsible for the unique observation of a root-expressed QTL. This study differs from that of Estañ et al. (2009) in that we measured yield QTL under stress as opposed to stress tolerance QTLs.

\section{Materials and methods}

Plant material and field trials

Whole-genome phenotypic surveys for the yield trait were performed in different field experiments: first in summer 2000, using the 75 ILs and their respective hybrid population (Eshed and Zamir 1995; http://www.sgn.cornell. edu/maps/pennellii_il/pennellii_il_map.html); secondly in summer 2001, using selected lines planted at two planting densities, namely (1) "single plants" with 1 plant per $\mathrm{m}^{2}$ under irrigated and dry conditions and (2) plots of $4 \mathrm{~m}^{2}$ with 14 plants in each (3.5 plants $\left./ \mathrm{m}^{2}\right)$, only under dry conditions. The experimental procedures were the same as in 2000, except that ten replications were used for each genotype in the "single plant" and eight replications in the plots.

Tests for the introgression effect under two irrigation treatments were performed in summer 2000 and 2001 using seven plants of each homozygous and heterozygous ILs and 100 plants of M82; the IL8-1 did not survive in the homozygous state. All open-field experiments were performed at the Western Galilee Experimental Station in Akko, Israel. Seedlings (35 days old) were transplanted in the field with $50 \mathrm{~cm}$ between plants and $2 \mathrm{~m}$ between rows (1 plant per $\mathrm{m}^{2}$ ). All the plants were sprinkler irrigated immediately after transplanting with $30 \mathrm{~m}^{3}$ of water for every $1,000 \mathrm{~m}^{2}$ of field area. For the rest of the growing period, the wet treatment was drip irrigated with $250 \mathrm{~m}^{3}$ of water per $1,000 \mathrm{~m}^{2}$, while no water was applied to the dry treatment. Figure 1 (supplementary) shows the water content of the soil during the experiment in the irrigated and dry fields, as determined by tensiometers and by measurements of moisture content in soil samples. Tensiometers were located at three different spots in each irrigation regime section and the readings were taken daily. Soil samples were taken from drillings at four depth points. The water content was calculated as the weight differential between fresh and oven-dried soil.

Grafting experiments were performed on 20-day-old seedlings in Ashkelon, Israel. Seedlings were cut above the cotyledons, using the shoot as scion and the remaining 
plant part as rootstock (Ashkelon, Israel). Grafts were made immediately after cutting the plants and grafting clips were used to hold together the graft union. Seedlings of M82 and each selected ILs were used for reciprocal grafts. Selfgrafted M82 plants were used as controls to estimate the grafting effects. Grafted plants were sown and transplanted in the field at the same time as the non-grafted plants. The field design and planting densities of the grafting experiments were exactly the same design as described for the "single plant".

Grafted and non-grafted IL8-3 genotypes were re-grown in an open-field experiment in Akko in summer 2008 under the same field design as described above. Red ripe fruits were harvested, rapidly skinned and pericarp sections taken and snap frozen in liquid nitrogen prior to metabolite profiling, exactly as described in Schauer et al. (2006).

In this study, "shoot" represents leaves, shoot, flowers and fruits, while "root" defines some part of the aboveground stem and the entire root system.

\section{Phenotyping}

In all experiments, fruits were harvested when $80-100 \%$ of the tomatoes were red. Plant vegetative weight $\left(\mathrm{PW}, \mathrm{kg} / \mathrm{m}^{2}\right)$ was determined by weighing only the vegetative tissue (after harvesting of the fruits) without the roots. Total fruit yield (TY, $\mathrm{kg} / \mathrm{m}^{2}$ ) per "single plant" or plot included both the red and green fruits. Mean fruit weight (FW, g/fruit) was estimated from a random sample of 20 representative fruits per plant or plot. Concentration of total soluble solids (BX, degrees Brix) was measured using a digital refractometer (RFM-80 BS) from a random sample of 10 fruits per "single plant" or 20 fruits per plot. Fruit number (FN, number of fruits $\left./ \mathrm{m}^{2}\right)$ was calculated by dividing TY $\left(\mathrm{g} / \mathrm{m}^{2}\right)$ by $\mathrm{FW}$ (g/fruit). The sugar output per plant was calculated as the product of BX and TY (BY, g sugar/plant).

Extraction, derivatization and analysis of polar metabolites using GC-MS

Metabolite analysis by GC-MS was carried out essentially as described by Fernie et al. (2004) and Lisec et al. (2006). The mass spectra were cross-referenced with those in the Golm Metabolome Database (Kopka et al. 2005).

\section{Statistical analyses and QTL mapping}

Statistical analyses were performed using the JMP V.5 software package (SAS Institute). For the IL-QTL mapping, each IL or ILH was compared to M82 and to each other to determine the phenotypic effect and the mode of inheritance of each introgressed region. The phenotypic effect of an IL represents the maximal effect of the introgressed $S$. pennellii allele, which was classified according to the mode of inheritance of the QTL. For recessive or additive QTL, the $\mathrm{IL}$ value represents the maximal effect. In cases of dominant QTL, the mean of the IL and ILH represent this maximum, and the phenotypic value of the overdominant QTL is represented by the value of the ILH. Comparisons of means were performed using the "Fit Y by X" function of the JMP program. Lines that showed significant difference from the M82 (at $P<0.05$, corrected for multiple comparisons; Dunnet 1955) were considered as possessing IL-QTL. M82 was tested at larger number of replications throughout all trials and compared to the specific ILs or ILHs. Unlike other mapping populations where QTL were mapped based on allelic comparison within segregating population (usually in the ratio of 1:2:1 for each genotypic class in F2 or $1: 1$ in $\mathrm{BC}$ ), in the introgression line case, each of the IL or ILHs was compared to the common control, M82. Due to the nature of this QTL mapping system, it is thus desirable that the calculated mean for the common control (M82) should be very reliable and therefore based on a larger number of replications. The unequal variance between M82 and each IL or ILH that is derived from the unequal number of replications is compensated by the stringency of the DUNNET test and by the fact that our findings were further validated in a second season.

\section{Mode of inheritance}

In addition to the common genetic components of variation ( $a$, additive effect and $d$, dominant deviation), we present here a somewhat different index that we calculated to describe the mode of inheritance for each QTL. The commonly used parameter $d /[a]$ ranges between -1 and +1 when the phenotypic value of the heterozygote is situated between its parents. However, $d /[a]$ is limited in describing overdominant QTL on a proportional scale, as its values can theoretically reach infinity in cases where the heterozygote is external to the parental range. We created the mode of inheritance index as a means to overcome the extreme $d \Lambda a]$ values that result from small and insignificant $a$ values that could lead to misrepresentation of overdominant QTL. Our rationale was to develop an intuitive parameter that would allow accurate representation of overdominant QTL relative to the best parent. The mode of inheritance index is a continuum that presents the position of each heterozygote IL (ILH) with respect to its homozygote parents (IL and M82). In cases in which the ILH phenotype is located between its parents, this index is principally similar to $d /[a]$ and generates values on a scale from 0 to 100 . The position of the ILH is calculated as the difference between the ILH and M82 divided by the difference between the IL and M82 (presented in percentage; 
$100 \times[$ ILH - M82]/[IL - M82]). Overdominant QTL are represented in mode of inheritance values that are higher than 100 or lower than 0 . Positive overdominance (ILH better than the best parent) will result in a value larger than 100 , which is calculated as the deviation of the ILH from the best parent (in percentage). The same applies to cases in which the ILH is lower than the low parent and results in a value smaller than 0 . Based on the mode of inheritance index, QTL are placed into qualitative categories that describe their mode of inheritance: $0-33=$ recessive, $34-66=$ additive, $67-100=$ dominant, $>100$ or $<0=$ overdominant. A detailed description of the calculation of the mode of inheritance of QTL is presented in Semel et al. (2007).

\section{Correlations}

The correlations between wet and dry treatments or between different years were calculated from a regression of genotype mean values. Correlations between traits were calculated using genotype means (for the whole population), or from values of the replicated M82 plants for correlations within M82.

\section{Heritability}

The broad sense heritability ( $h 2)$, which is $\sigma_{\mathrm{G}}^{2} / \sigma_{\mathrm{G}+\mathrm{E}}^{2}$, was calculated for each trait using the "fit model" function. Genotype was defined as a factor with random effect and the genetic variation was calculated as percentage of the total variation (genetic + environmental).

\section{Results}

Analysis of yield-related traits of the parents and their F1 hybrids

The phenotypic values for the yield-related traits are presented for M82, S. pennellii and the interspecific F1 hybrid (Table 1). It is important to note that $S$. pennellii was in fact sterile under our field conditions. Strong heterosis was detected for the interspecific F1 hybrid, with PW values being 21-fold higher than both parents in the wet and 11 times higher than the best parent in the dry field. For TY, FW and FN, F1 showed lower values than M82. BX values of F1 were increased by $100 \%$ compared to M82 in both environments. Mean BY values, which represent the product of $\mathrm{TY}$ and $\mathrm{BX}$, were similar between $\mathrm{F} 1$ and M82 in the wet field. These results confirm not only the existence of exceptionally strong hybrid vigor with respect to vegetative growth detailed in Semel et al. (2007), but also the inferiority of the interspecific hybrid compared to the cultivated tomato with respect to fruit yield components.

Analysis of six yield-related traits in dry and wet fields

In the summer of 2000, the 75 ILs and their hybrids with M82 (ILH) were tested in dry and wet fields. Four yieldrelated phenotypic traits were measured (plant weight (PW), total yield (TY), fruit weight (FW) and brix (BX)) and an additional two derived parameters were calculated [fruit number (FN) and brix yield (BY)]. The statistical and genetic characteristics for these traits, at the whole population level, are presented in Table 1. In general, drought stress affected both the mean values of the traits and the components of variation. A comparison between the environments revealed differences in the heritability values, such that the heritabilities for most traits were higher in the wet environment than in the dry one. FW was an exception as its heritability did not differ between the extreme environments. A comparison between the mean mode of inheritance indices for the different traits revealed large differences that were consistent in the diverse environments. PW showed mode of inheritance indices of 49 and 51 in the wet and dry fields, respectively, indicating a general additive mode of inheritance. BX was also additively inherited with mode of inheritance values of 54 in the wet field and 36 in the dry one. All three direct yield parameters, which were also strongly correlated (Table 2), showed an average overdominant mode of inheritance. BY showed the strongest overdominance, with values of 129 under wet and 119 under dry conditions. An interesting result was the increase in the overdominance of FW in the dry field, in contrast to TY, FN and BY. Figure 1 presents the frequency distribution of the means for each IL or ILH for the six phenotypic traits. For all of them, the distribution was normal, with M82 located very close to the population mean. A strong impact of drought stress on the measured traits was concluded based on a comparison of the M82 means between the dry and wet fields (Table 1; Fig. 1). For PW, there was a reduction of $43 \%$ and TY was reduced by more than $50 \%$ in the dry compared to the wet field. FW was reduced by $25 \%$, whereas $\mathrm{BX}$ values were increased by more than $30 \%$ as a result of drought stress. The coefficient of variation $(\mathrm{CV})$ of the means was generally lower under dry conditions; however, for FW, the CVs under dry and wet conditions were similar. The reduced expression of genetic variation in the dry field, in the form of reduced $\mathrm{CV}$ values, was probably the reason for the reduced heritabilities for most of the traits in this environment (Table 1). Another phenomenon that could be observed by looking at the frequency distributions was the existence of ILs that showed phenotypic values external to the range between the parents. This transgressive 
Table 1 Means and components of genetic variation for six phenotypic traits, in the parents, the ILs and the ILHs

\begin{tabular}{|c|c|c|c|c|c|c|c|c|c|c|}
\hline Trait & Units & M82-Mean & F1-Mean & S.pennellii-Mean & IL-Mean & ILH-Mean & Pop-Mean & $\mathrm{CV}^{\mathrm{a}}$ & $\mathrm{H}^{2}, \mathrm{~b}$ & $\begin{array}{l}\text { Number } \\
\text { of QTL }\end{array}$ \\
\hline \multicolumn{11}{|l|}{ Wet } \\
\hline PW & kg/plant & 1.2 & 25.0 & 1.23 & 2.2 & 1.7 & 1.9 & 93 & 0.66 & 30 \\
\hline TY & $\mathrm{kg} /$ plant & 8.5 & 4.0 & No yield & 6.7 & 10.0 & 8.3 & 54 & 0.48 & 23 \\
\hline FW & $\mathrm{g} /$ fruit & 67.4 & 3.1 & No yield & 62 & 70 & 66 & 20 & 0.61 & 36 \\
\hline $\mathrm{BX}$ & Brix \% & 3.4 & 7.8 & No yield & 3.9 & 3.7 & 3.7 & 16 & 0.48 & 26 \\
\hline $\mathrm{FN}$ & $\mathrm{N}$ fruit/plant & 124.7 & 59.7 & No yield & 107 & 141 & 123 & 51 & 0.51 & 16 \\
\hline BY & g sugar/plant & 290.0 & 312.0 & No yield & 262 & 374 & 311 & 58 & 0.45 & 27 \\
\hline \multicolumn{11}{|l|}{ Dry } \\
\hline PW & kg/plant & 0.7 & 9.6 & 0.83 & 0.9 & 0.8 & 0.9 & 53 & 0.48 & 24 \\
\hline TY & kg/plant & 3.9 & NA & No yield & 3.5 & 4.4 & 3.9 & 41 & 0.4 & 16 \\
\hline FW & $\mathrm{g} /$ fruit & 51.3 & 1.9 & No yield & 49 & 57 & 52 & 21 & 0.62 & 27 \\
\hline $\mathrm{BX}$ & Brix \% & 4.5 & 8.7 & No yield & 5.0 & 4.7 & 4.8 & 14 & 0.43 & 21 \\
\hline $\mathrm{FN}$ & $\mathrm{N}$ fruit/plant & 76.3 & NA & No yield & 73 & 80 & 76 & 42 & 0.38 & 8 \\
\hline BY & g sugar/plant & 170.5 & NA & No yield & 180 & 209 & 191 & 42 & 0.35 & 18 \\
\hline
\end{tabular}

Mean values and components of genetic variation for six traits ( $P W$ plant weight; $T Y$ total yield; $F W$ fruit weight; $B X$ brix; $F N$ fruit number; $B Y$ Brix $\times$ total yield) as measured in Akko 2000 under dry and wet field conditions. Included are values for M82, S. pennellii, their F1 hybrid, 75 ILs, 75 ILHs (ILs $\times$ M82) and for the entire population (ILs + ILHs). M82 had 100 replications under each irrigation regime. Each IL or ILH was in seven replications under each irrigation regime

${ }^{a}$ Coefficient of variation $(\mathrm{CV}, \%)$ for genotype means

b Broad sense heritability (\%), calculated as $\sigma_{\mathrm{G}}^{2} / \sigma_{\mathrm{G}+\mathrm{E}}^{2}$

c Number of significant IL-QTL per trait

segregation highlights hidden genetic variation in the parents that was masked by epistatic interactions of their genomes, but was freed from these restrictions in the ILs (DeVicente and Tanksley 1993; Eshed and Zamir 1995).

\section{Phenotypic correlations between traits}

The correlations between traits were estimated by regressing phenotypic values of one trait on those of another. Table 2 presents the correlations between traits at the IL population level, and for the inbred M82, as calculated for the wet and dry conditions. Comparison between the dry and wet correlation data indicated a strong conservation of relationships between traits. The best way to evaluate the level of this conservation is by correlating the double-trait correlations between the two environments, such that each point represents a correlation between two traits, and the $\mathrm{X}$ and $\mathrm{Y}$ values of this point are the correlation values in each of the diverse environments. Indeed, the correlations between the dry and wet environments were very high, with values of $R=0.95$ for both the ILs and the M82, indicating that the trait relationships were maintained under diverse environmental conditions. On the other hand, when we correlated the correlations for the whole population with the correlations in M82 (using the same rationale, but on diverse genetic environments), there was a weaker relationship: $R=0.8$ in the wet and 0.77 in the dry environments, with mean $R$ values that were lower with the ILs compared to M82. This resulted from the variability that existed among the lines in the population with regard to correlations between traits. BY is a derived parameter that is calculated as the product of $\mathrm{BX}$ and $\mathrm{TY}$ and represents the total sugar production in fruits of a tomato plant. Variation in BY was explained by the variation in TY $(R=0.97$ in the wet and 0.93 in the dry, Table 2), while the correlations between $\mathrm{BY}$ and $\mathrm{BX}$ were weaker $(R=0.13$ in the wet environment and $R=0.01$ in the dry one). TY was positively correlated with PW for M82, but not for the ILs, under both wet and dry conditions. The other yield components, as indicated by the correlations, are FW and FN, with the latter being more dominant in its contribution. The phenotypic correlations between the dry and wet environments were calculated for all six traits based on the IL means (Table $2 \mathrm{c}$ ). The correlations were strong and highly significant, and ranged between 0.72 and 0.82 .

QTL mapping in the dry and wet environments

Mapping IL-QTL

The phenotypic effect (as percentage of difference from M82) and mode of inheritance of ILs with significant 
Table 2 Correlations between traits and irrigation regimes

\begin{tabular}{|c|c|c|c|c|c|}
\hline Trait & PW & FW & BX & TY & BY \\
\hline \multicolumn{6}{|c|}{ (a) Wet } \\
\hline \multirow[t]{2}{*}{ FW } & $0.41 *$ & & & & \\
\hline & -0.16 & & & & \\
\hline \multirow[t]{2}{*}{ BX } & 0.41* & 0.06 & & & \\
\hline & $0.72 *$ & $-0.31 *$ & & & \\
\hline \multirow[t]{2}{*}{ TY } & 0.71* & 0.55* & 0.22 & & \\
\hline & 0.19 & $0.58 *$ & -0.09 & & \\
\hline \multirow[t]{2}{*}{ BY } & 0.75* & $0.53 *$ & $0.44 *$ & $0.97^{*}$ & \\
\hline & $\mathbf{0 . 3 4} *$ & 0.52* & 0.13 & $\mathbf{0 . 9 7} *$ & \\
\hline \multirow[t]{2}{*}{ FN } & $0.62 *$ & 0.27 & 0.19 & 0.94* & 0.9* \\
\hline & 0.26 & 0.22 & -0.01 & 0.9* & 0.88 \\
\hline \multicolumn{6}{|c|}{ (b) Dry } \\
\hline \multirow[t]{2}{*}{ FW } & 0.19 & & & & \\
\hline & $-\mathbf{0 . 3 3}^{*}$ & & & & \\
\hline \multirow[t]{2}{*}{ BX } & -0.09 & $-0.54 *$ & & & \\
\hline & 0.6* & $-\mathbf{0 . 5}{ }^{*}$ & & & \\
\hline \multirow[t]{2}{*}{ TY } & 0.8* & $0.45 *$ & $-0.32 *$ & & \\
\hline & 0.15 & $0.62 *$ & -0.26 & & \\
\hline \multirow[t]{2}{*}{ BY } & 0.82* & 0.35* & -0.07 & 0.96* & \\
\hline & 0.39* & $\mathbf{0 . 4 5} *$ & 0.01 & $\mathbf{0 . 9 3}^{*}$ & \\
\hline \multirow[t]{2}{*}{ FN } & 0.81* & 0.1 & -0.18 & 0.92* & 0.92 \\
\hline & 0.41* & -0.01 & 0.03 & 0.74 & 0.8* \\
\hline
\end{tabular}

(c) $R$ between dry and wet

$\begin{array}{lll}\text { PW } & 0.73 & 7 \mathrm{E}-26 \\ \text { TY } & 0.76 & 4 \mathrm{E}-28 \\ \text { BX } & 0.77 & 1 \mathrm{E}-29 \\ \text { FW } & 0.81 & 3 \mathrm{E}-35 \\ \text { BY } & 0.72 & 6 \mathrm{E}-24 \\ \text { FN } & 0.82 & 2 \mathrm{E}-35\end{array}$

Correlations between traits, in the whole population (ILs; lower number in each cell) and in M82 (upper number in each cell) in the wet (a) and dry (b) fields. At the whole population level, correlations were calculated using mean values of 150 genotypes $(N=150)$. For M82, correlations were calculated using values of M82 plants from the wet and dry treatments separately ( $N=100$ from each). Bolded values are significant at $P<0.01$, bolded + asterisk are significant values at $P<0.001$. (c) Phenotypic correlations between genotype means in the dry and wet fields for the six traits. $P W$ plant weight; $T Y$ total yield; $F W$ fruit weight; $B X$ brix; $F N$ fruit number; $B Y$ Brix $\times$ total yield

effects, in the dry or wet fields, are presented in Table 1A and B (Supplementary). Lines that showed a significant effect compared to the common control (M82) are indicated. To confirm these results regarding the significant QTL, 30 lines (ILs and ILHs) that showed a significant effect for the measured traits were re-evaluated in Akko in the summer of 2001 under a similar experimental design in wet and dry fields.

\section{Plant weight}

Thirty ILs had a significant effect on plant weight (PW) in the wet field and 24 in the dry one (Supplementary Table 1). In both environments, most of the QTL had increasing effects compared to M82 (27 compared to 3 in the wet and 24 versus zero in the dry environment; Fig. 2). About onethird of the increasing QTL were recessive (9/27 in the wet group and 9/24 in the dry), and the rest were almost equally distributed between additive and dominant QTL in both environments. Eighteen of the IL-QTL for PW showed conserved expression as they were detected in both environments. A total of 12 IL-QTL showed wet-specific expression and 6 were drought specific (Fig. 2).

\section{Total yield}

As much as 23 significant IL-QTL were identified in the wet field and 16 in the dry one (Supplementary Table 1). Nine and eight of the QTL had increasing effects in the wet and dry environments, respectively. More than half of these showed an overdominant mode of inheritance (7/9 for the wet conditions and 4/8 for the dry). In both environments, most of the decreasing QTL showed recessive mode of inheritance (12/16 for the wet conditions and $8 / 10$ for the dry; Fig. 2). Thirteen of the IL-QTL for TY were conserved. Ten QTL showed wet-specific expression and only three were drought specific.

\section{Brix}

A total of 26 significant IL-QTL were identified in the wet field and 21 in the dry one (Supplementary Table 1). BX was the trait that showed the lowest level of transgressive segregation, as none of the lines showed significant decreasing effect compared to M82 at our significance level. Among the increasing QTL, there was a relatively equal distribution among the recessive, additive and dominant mode of inheritances, and none of the QTL for this trait showed overdominance (Fig. 2). Seventeen of the QTL for BX were conserved. Nine QTL showed wet-specific expression and four were drought specific.

\section{Fruit weight}

A total of 37 IL-QTL were identified in the wet field and 27 in the dry one (Supplementary Table 1). The distribution of increasing and decreasing QTL for fruit weight (FW) is relatively symmetric in the dry (14 increasing and 13 decreasing), while in the wet there are more than twice as many negative QTL (11 increasing and 26 decreasing). The distribution of mode of inheritance among QTL in each direction was different. Whereas for the increasing QTL 
Fig. 1 Frequency distribution of the IL and ILH means for six phenotypic traits in the dry and wet fields. Arrows on each figure indicate the mean value of M82 in the dry (D) and wet (W) fields
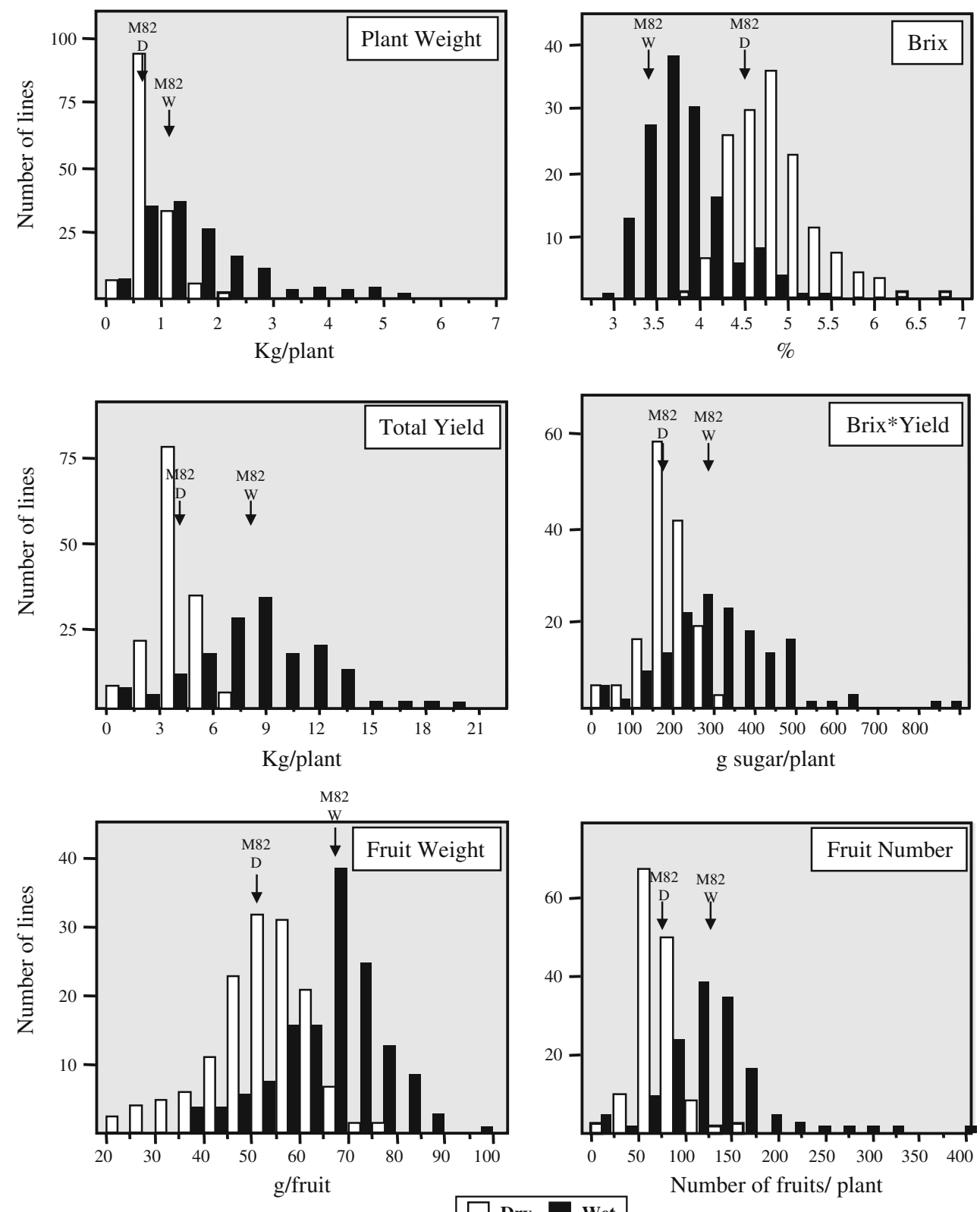

Dry Wet

$18.1 \%$ were additive, $45.6 \%$ were dominant and $27.1 \%$ were overdominant, in the wet and dry combined for the decreasing QTL, $65.61 \%$ were recessive, $7.2 \%$ were additive and only $2.7 \%$ were dominant (Fig. 2). Twenty of the QTL for FW were conserved. Sixteen QTL showed wet-specific expression and seven were drought specific.

\section{Brix yield}

A total of 29 significant IL-QTL were identified in the wet field and 18 in the dry one (Supplementary Table 1). Although highly correlated with TY, the picture for Brix yield (BY) was somewhat different, with more increasing QTL (18 and 13 in the wet and dry, respectively) than decreasing ones (11 and 5 in the wet and dry, respectively). However, their partition into mode of inheritance categories was similar: for the increasing QTL, 11/18 and 4/13 were overdominant in the wet and dry, respectively. At the decreasing side, 6/11 were recessive in the wet, and 5/5 in the dry (Supplementary Table 1; Fig. 2). Eleven of the QTL for BY were conserved, 16 showed wet-specific expression and 7 were drought specific.

\section{Fruit number}

Eighteen significant IL-QTL were identified in the wet treatment, and 9 in the dry one (Supplementary Table 1). In correlation with TY, most of the increasing QTL were 
Fig. 2 Distributions of IL-QTL according to their mode of inheritance and direction of their effect in the dry (D) and wet (W) experiments. Each bar represents the number of QTL per trait. Above the zero line are the numbers of increasing QTL, and below are the numbers of decreasing ones. Below the bars for each trait are the numbers of IL-QTL for that trait according to their mode of expression: conserved, detected in both environments; wet specific, detected only in the wet field; dry specific, detected only in the dry field. $P W$ plant weight; $T Y$ total yield; $F W$ fruit weight; $B X$ Brix; $F N$ fruit number; $B Y$ Brix $\times$ total yield

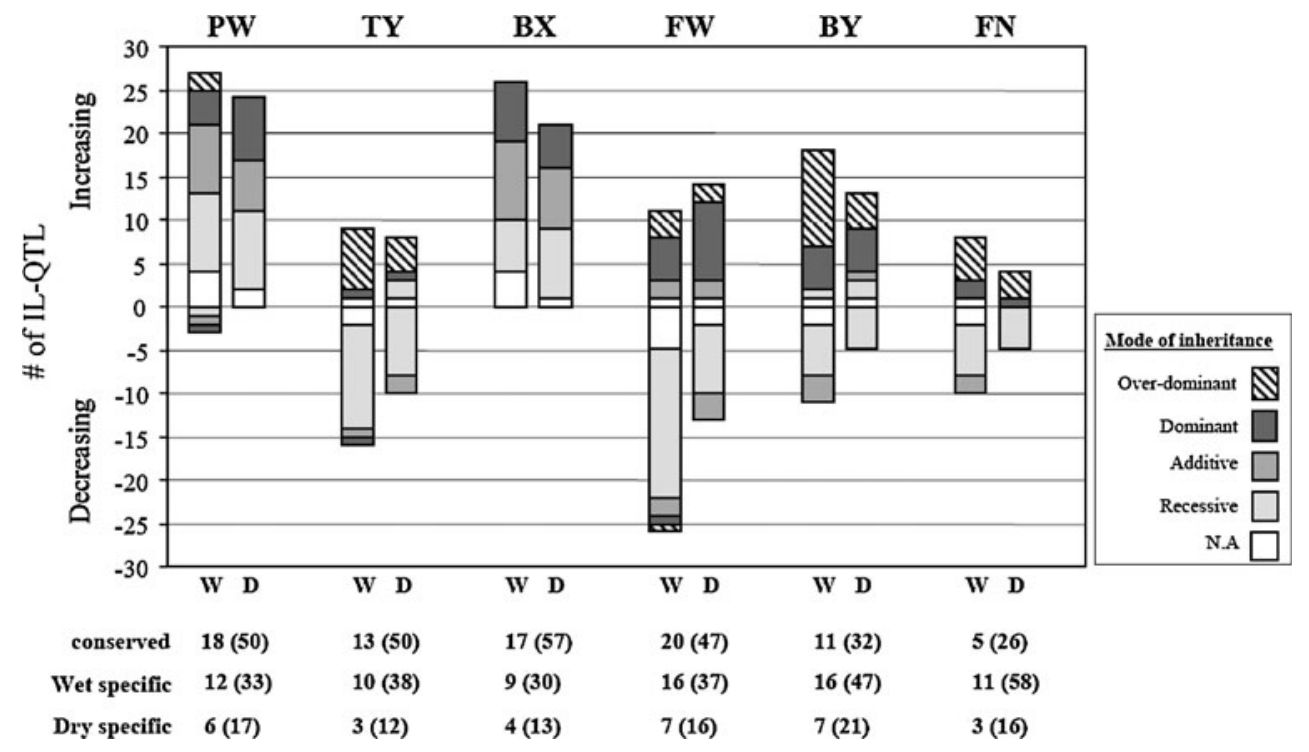

overdominant ( $5 / 8$ for the wet and $3 / 4$ for the dry). Most of the decreasing QTL were recessive $(6 / 10$ and $5 / 5$ in the wet and dry, respectively; Supplementary Table 1; Fig. 2). The largest proportion of environment-specific QTL was observed for FN. Five of the QTL were conserved; 11 QTL showed wet-specific expression and 3 were drought specific.

Localization of yield-related QTL expression to roots and shoots

To explore a physiological dimension of the yield variation, we asked the following questions using a reciprocal grafting strategy: (1) which plant part (root or shoot) contributes more to the variation in yield-related phenotypes? (2) Can we map consistent root- or shoot-specific yield QTL using the IL population? To address these questions, reciprocal grafting experiments were conducted over several field seasons between 2003 and 2005. To identify root or shoot effects, each grafted IL was compared to M82 and to its corresponding non-grafted IL plants. Shoot-specific QTL were defined in cases where an IL grafted as a shoot onto an M82 rootstock had a phenotype similar to that of the non-grafted IL, and both of them differed from M82. Root-specific QTL were defined in cases where the root-grafted IL (M82 grafted onto an IL rootstock) had a phenotype similar to the non-grafted IL, and both of them were different from M82. A third possible scenario was an interaction between root and shoot, such that neither the shoot graft nor the root graft would have the same effect as the significant non-grafted IL. Another more complex possibility (which is presented below) may arise in cases in which the root and shoot have contrasting effects that interact, and only one of them is reflected in the non-grafted plants. In such cases, the grafting enabled us to reveal hidden root or shoot QTL.

A total of 23 ILs (and the M82 control) with significant effects on the yield-related parameters were selected for the experiment in summer of 2003 under wet conditions. Eight of these lines were tested also in dry field. Each IL (and the M82 control) was grafted as a shoot onto M82, and in a reciprocal manner, M82 was grafted onto each IL. All the genotypes were also tested as non-grafted plants. Table 3 summarizes the results for the phenotypic effects of the root or shoot on each of the tested genotypes for the six yield-related traits (at the wet field). Self-grafted M82 displayed no significant differences to non-grafted M82 for any of the traits. ILH1-2 provides an example of a shootspecific BY QTL, as the effect of the non-grafted line was $+96 \%(P<0.01)$, the shoot effect was $+65 \%(P<0.01)$ and the root effect was $-7 \%$ (not significant). As seen in Table 3, in most cases non-grafted genotypes also showed a significant effect when grafted as a shoot (S). To quantify this observation, we calculated the heritability of each trait under each of the tested groups (i.e., 'shoot effect', 'root effect' and non-grafted). As presented in Table 4, heritability of all the traits in the 'shoot effect' group (mean $=0.52$ and 0.51 at the wet and dry conditions; respectively) was similar to that in the non-grafted plants (mean $=0.51$ and 0.62 at the wet and dry; respectively), while in the 'root effect' group the heritability was substantially lower, with an average of 0.05 in the wet and 0.01 in the dry. To confirm that the genetic variation in shoot effect not only explained the same amount of phenotypic variation as non-grafted plants, but also in a corresponding manner, we correlated between the ILs mean values among the different groups. For all of the traits in the wet experiment, the non-grafted IL correlations with 
the shoot effects ranged between 0.87 and 0.95 with a highly significant average of 0.9 , whereas the correlations of the non-grafted IL with root effects ranged between -0.24 and 0.14 with a non-significant average of -0.05 (Table 4). This trend was consistent also in the dry experiment, although there were only eight lines that were tested (Table 4). These results clearly indicate that on the tested population, yield is determined mainly by shootexpressed genetic variation.

In spite of the domination of shoot traits as described above, we were able to identify two lines that exhibited significant yield-improving root effects (IL8-3 and IL2-1; Table 3). Interestingly, on both lines the positive root effect was accompanied by a negative contrasting shoot effect. For example, non-grafted IL2-1 reduced BY by $65 \%$ compared to M82; the shoot effect of this line was a reduction of $72 \%$, while on the rootstock side, this genotype showed a significant increase of 40\%. For IL8-3, the trend was similar: the non-grafted IL reduced BY by $51 \%$, the shoot effect was responsible for a reduction of
$36 \%$, and the root caused an increase of $78 \%$ (Table 3 ). To confirm these root effects, which were in contrast to the general trend that was observed in this population, we tested IL8-3 and IL2-1 again in the summers of 2004 and 2005 under similar experimental design. The root effect of IL2-1 was less consistent (although the same trend was observed in 2 years). IL8-3, on the other hand, exhibited a consistent root effect. The results of the 3 years for IL8-3 are presented in Fig. 3 where the opposite root effect (relative to the shoot) is very prominent for TY, BY and FN. While this root QTL significantly improved TY, BY and FN, it did not have significant effect on PW, BX and FW in any of the experiments. This is an interesting result because it might indicate an involvement of roots in developmental processes, such as transition from vegetative to reproductive or efficiency of fruit setting. With respect to the mode of inheritance, the root QTL showed a recessive one as the heterozygote IL did not show any significant consistent root effect (Table 3).

Table 3 Phenotypic effects (as $\Delta \% \mathrm{M} 82$ ) of root and shoot QTL for six yield-related traits, over 20 genotypes

\begin{tabular}{|c|c|c|c|c|c|c|c|c|c|c|c|c|c|c|c|c|c|c|}
\hline \multirow[t]{2}{*}{ Genotype } & \multicolumn{3}{|c|}{ Plant weight } & \multicolumn{3}{|c|}{ Total Yield } & \multicolumn{3}{|c|}{ Fruit Weight } & \multicolumn{3}{|l|}{ Brix } & \multicolumn{3}{|c|}{ Brix $\times$ yield } & \multicolumn{3}{|c|}{ Fruit number } \\
\hline & WT & $S$ & $R$ & WT & $S$ & $R$ & WT & $S$ & $R$ & WT & $S$ & $R$ & WT & $S$ & $R$ & WT & $S$ & $R$ \\
\hline ILH1-2 & 116 & 84 & -14 & 74 & 49 & -6 & 7 & 3 & -1 & 12 & 10 & -8 & 96 & 65 & -7 & 70 & 48 & -7 \\
\hline IL2-1 & -63 & -60 & 24 & -59 & -69 & 43 & 7 & -11 & 7 & -15 & -13 & -2 & -65 & -72 & 40 & -65 & -66 & 35 \\
\hline ILH2-4 & 97 & 64 & 22 & 0 & 24 & 18 & 5 & 15 & 2 & 18 & 8 & 4 & 18 & 35 & 24 & -4 & 8 & 15 \\
\hline IL2-5 & 284 & 246 & 54 & 0 & -21 & 44 & -52 & -45 & 6 & 24 & 23 & 1 & 27 & 0 & 44 & 104 & 40 & 35 \\
\hline ILH2-5 & 96 & 88 & -19 & 60 & 60 & -4 & $-\mathbf{3 0}$ & -33 & 4 & 4 & 14 & -2 & 74 & 83 & -7 & 108 & 145 & 3 \\
\hline IL2-6-5 & 32 & 32 & 16 & 37 & 24 & 21 & 33 & 23 & 6 & 12 & 17 & 2 & 61 & 45 & 24 & 6 & 3 & 19 \\
\hline IL4-2 & -45 & -48 & 9 & -35 & -36 & 37 & -2 & -11 & 8 & 4 & -3 & -11 & -32 & -35 & 23 & -33 & -26 & 28 \\
\hline IL5-2 & 159 & 189 & 31 & 32 & -10 & 39 & -3 & -16 & -3 & 40 & 39 & 1 & 84 & 18 & 45 & 30 & -4 & 42 \\
\hline IL7-4 & 76 & 27 & 12 & -1 & -2 & 39 & 18 & 21 & 9 & 4 & 4 & -1 & 3 & 9 & 39 & -17 & -21 & 32 \\
\hline IL7-5 & 48 & -3 & 36 & 38 & 2 & 40 & 13 & 19 & 7 & 10 & 5 & 4 & 50 & 9 & 49 & 26 & -15 & 30 \\
\hline IL8-3 & 117 & 69 & 44 & -63 & -52 & 77 & -17 & -12 & 10 & 32 & 34 & 1 & -51 & -36 & 78 & -55 & -47 & 64 \\
\hline ILH8-3 & 89 & 37 & 54 & 66 & 31 & 35 & 5 & 5 & 1 & 23 & 12 & 3 & 105 & 49 & 39 & 60 & 29 & 36 \\
\hline IL9-2 & 120 & 218 & -26 & -47 & -25 & -4 & -15 & -8 & 6 & 47 & 41 & -5 & -23 & 5 & -7 & -40 & -20 & -6 \\
\hline IL10-3 & 54 & 61 & -9 & 68 & 50 & 0 & 25 & 20 & 2 & 6 & 9 & -2 & 78 & 64 & -1 & 35 & 26 & 0 \\
\hline IL12-1-1 & 85 & 114 & 0 & 72 & 87 & 24 & 42 & 36 & 8 & 12 & 10 & -4 & 96 & 105 & 19 & 23 & 40 & 17 \\
\hline IL12-4-1 & 27 & -1 & 29 & 18 & -37 & 39 & 36 & 23 & 0 & 8 & 9 & 5 & 28 & -32 & 49 & -16 & -51 & 34 \\
\hline $7+9$ & 70 & 30 & 2 & 47 & 34 & 19 & 3 & 12 & 2 & 32 & 25 & -7 & 93 & 67 & 8 & 45 & 21 & 12 \\
\hline ILH7 $+9+8$ & 88 & 69 & 25 & 69 & 79 & 37 & 5 & 6 & 9 & 36 & 28 & 2 & 130 & 130 & 42 & 65 & 75 & 29 \\
\hline subIL6-3 & 235 & 290 & 13 & 119 & 150 & 27 & 22 & 19 & 13 & 42 & 44 & 0 & 210 & 262 & 23 & 81 & 118 & 9 \\
\hline 3155 & 56 & 73 & 13 & 47 & 44 & 25 & 40 & 35 & 2 & 37 & 35 & -2 & 101 & 93 & 30 & 5 & 6 & 20 \\
\hline m82 (n g) & 13 & & & 18 & & & 5 & & & 4 & & & 25 & & & 12 & & \\
\hline
\end{tabular}

For each genotype, the effects (means of 10 replications) are presented as percentage difference from M82 grafted on itself. $R$ represents the root effect (M82 grafted on IL); $S$ represents the shoot effect (IL grafted on M82); WT is the non-grafted IL. Bolded values indicate significant effects $(P<0.05)$. The bottom row presents the values of non-grafted M82 (M82 $\mathrm{n}$ g) showing no grafting treatment effects for the common control. 3155 is a commercial hybrid. ID M82 is a nearly isogenic indeterminate line with a small introgression on chromosome 6 that includes the S. pennellii SP locus 
Table 4 Comparison of heritabilities and correlations with non-grafted phenotypes for the six measured traits between the 'shoot effect' and 'root effect' groups

\begin{tabular}{|c|c|c|c|c|c|c|c|}
\hline \multirow[t]{2}{*}{ Factor } & \multirow[t]{2}{*}{ Trait } & \multicolumn{3}{|l|}{ Wet } & \multicolumn{3}{|l|}{ Dry } \\
\hline & & NG & $S$ & $R$ & NG & $S$ & $R$ \\
\hline \multirow[t]{6}{*}{ Heritability } & PW & 0.51 & 0.49 & 0.1 & 0.42 & 0.47 & 0 \\
\hline & TY & 0.44 & 0.5 & 0.06 & 0.64 & 0.35 & 0.03 \\
\hline & $\mathrm{BX}$ & 0.6 & 0.57 & 0.04 & 0.3 & 0.46 & 0 \\
\hline & FW & 0.55 & 0.52 & 0 & 0.87 & 0.86 & 0 \\
\hline & BY & 0.49 & 0.56 & 0.06 & 0.68 & 0.28 & 0.04 \\
\hline & FN & 0.44 & 0.51 & 0.04 & 0.81 & 0.65 & 0.01 \\
\hline Mean & & 0.505 & 0.525 & 0.05 & 0.62 & 0.5117 & $\mathbf{0 . 0 1 3 3}$ \\
\hline \multirow[t]{6}{*}{ Correlation with non-grafted } & PW & & 0.9 & 0.14 & & 0.63 & -0.66 \\
\hline & TY & & 0.87 & -0.22 & & 0.64 & -0.38 \\
\hline & $\mathrm{BX}$ & & 0.95 & 0.04 & & 0.75 & -0.38 \\
\hline & FW & & 0.94 & 0.05 & & 0.96 & -0.28 \\
\hline & BY & & 0.88 & -0.12 & & 0.79 & -0.32 \\
\hline & FN & & 0.85 & -0.24 & & 0.89 & -0.56 \\
\hline Mean & & & 0.8983 & -0.05833 & & 0.7767 & -0.43 \\
\hline
\end{tabular}

Heritabilities at the wet experiment were calculated from 23 lines with 10 replications. In the dry experiment, there were eight lines with ten replications. $S$ shoot effect: group where all the lines were tested as shoot grafted onto M82 rootstock. $R$ root effect group where all the lines were tested as rootstock that M82 was grafted onto. $N G$ non-grafted: group of non-grafted plants. Each of the lines was represented at each of the groups. $P W$ plant weight; $T Y$ total yield; $F W$ fruit weight; $B X$ brix; $F N$ fruit number; $B Y$ brix $\times$ total yield. For the correlations, bolded values are significant at $P<0.05$ or less. Correlations; bold values are significant at $P<0.05$ or less. Values for the dry condition are calculated only from eight lines that were tested (trend is still similar to the wet)

Interaction between root and shoot effects

The results for IL8-3 (Fig. 3) indicated interactions existing between the shoot and the root on this line, such that for the non-grafted plants the shoot effect nullified the root action. Our grafting approach enabled the detection of this hidden root QTL when tested in a neutral shoot background (M82). To further investigate the relation between root and shoot and their effect on yield production, we chose IL7 + 9, a line that harbors two introgressions (IL7-5-5 and IL9-2-5). This line had a strong improving effect on BY and was well characterized as shoot specific over two seasons. We decided to test the interactions between root and shoot by grafting this line on M82 and on a BY improving rootstock ( $\mathrm{F} 1$ between M82 and S. pennellii). Figure 4 summarizes the results of this experiment in wet and dry fields. For the independent effects, both the IL7 +9 shoot and the F1 root improved BY significantly by 50 and $20 \%$, respectively, at the irrigated field, and by 50 and $50 \%$ at the dry field, compared to M82. However, no interaction was found between the shoot and the root effects as determined by two-way ANOVA. In fact, an insignificant more than additive effect was observed when the IL7 +9 shoot was grafted on the F1 root as this combination improved BY at $80 \%$ in the irrigated and $140 \%$ in the dry field. These results provide example for independent actions of shoot and root, as their combination resulted in additive yield improvements. IL7 +9 and IL8-3 represent two different examples for the relations between shoot and root; Fig. 5 shows this difference on the basis of the deviations of the observed values of the selfgrafted and F1-root-grafted ILs from expected values based on complete additivity between root and shoot. For IL7 +9 , the observed values of both the self-grafted plants (IL7 +9 shoot on IL7 +9 root) and F1-root-grafted plants (IL7 + 9 shoot on F1 root) were not different from the expected, reflecting additive effect. On the other hand for IL8-3, on both the self-grafted and the F1-root grafts, the expected values were significantly higher than the observed, which is another evidence for the less than additive interaction imposed by the IL8-3 shoot.

Metabolic profiling of IL8-3 derived material

In an attempt to characterize the physiological basis of the root effect in IL-8-3, we replanted the IL8-3 in non-grafted state and with M82 scions grafted onto rootstock at the Akko field site in 2008. We rapidly harvested pericarp tissue from red ripe tissue of the two genotypes and of an ungrafted M82 control line and quenched metabolism in this tissue by snap freezing as described in Schauer et al. (2006). Of the 15 QTL observed in the ungrafted IL-8-3 line eight (those for glycerol 3-P, xylose, sucrose, malate, fumarate, tyrosine, proline, isoleucine, $\gamma$-amino butyric 

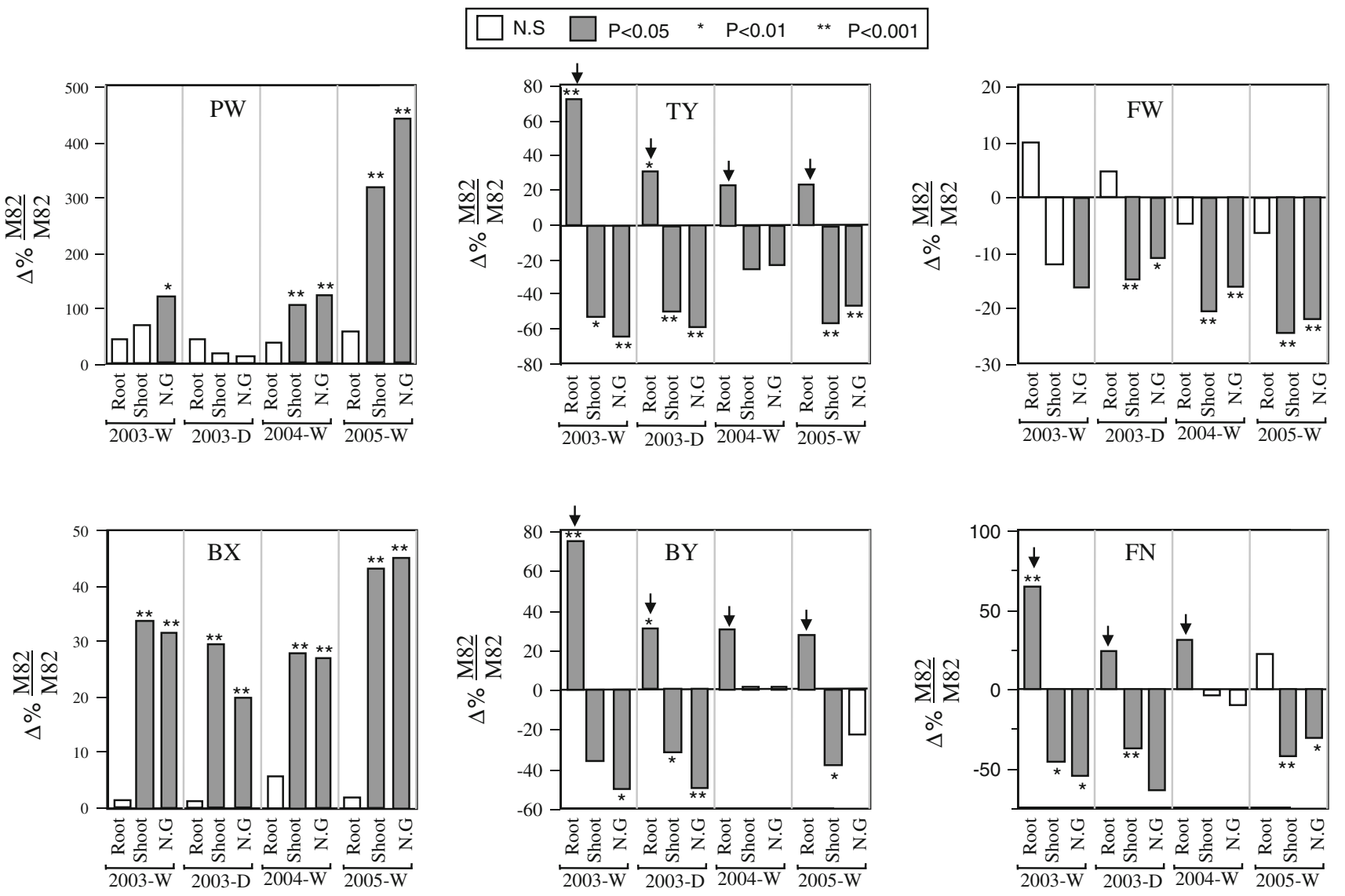

Fig. 3 Reciprocal-grafting analysis of IL8-3 shoot and root effects on yield-related traits over four experiments. For all traits, empty bars represent a non-significant effect. Gray bars are significantly different from M82 at $P<0.05$. *Significance at $P<0.01$; **Significance at $P<0.001$. All the values are presented as percentage difference from

acid (GABA) and $\beta$-alanine have been described previously, Schauer et al. 2006, 2008). Of the 15 QTL observed in the homozygous IL, 7 were also observed, albeit at a lesser magnitude, in the pericarp of fruit harvested following grafting of a wild-type (M82) scion onto the IL rootstock ( $\beta$-alanine, GABA, isoleucine, proline, threonine, valine and glycerol 3-phosphate) suggesting that these QTL were, at least partially, root determined (Fig. 6).

\section{Discussion}

Mode of inheritance of IL-QTL

The ILs were tested as homozygotes and heterozygotes (ILHs), thus facilitating the determination of the mode of inheritance of each QTL and the identification of overdominant QTL. Such an approach for dissecting traits that show heterosis has been demonstrated for rice (Xiao et al. 1995; Li et al. 2001), tomato (Semel et al. 2006; Schauer
M82 grafted on itself. Root: root effect, shoot: shoot effect, NG: nongrafted effect. Black arrows indicate on the contrasting root effects. $P W$ plant weight; $T Y$ total yield; $F W$ fruit weight; $B X$ Brix; $F N$ fruit number; $B Y$ Brix $\times$ total yield

et al. 2008) and Arabidopsis (Lisec et al. 2009). Recent advances in understanding the molecular basis of heterosis have additionally been made by detailed large-scale studies of gene expression and epistasis in rice, maize and Arabidopsis (Li et al. 2001; Hua et al. 2003; Auger et al. 2004; Vuylsteke et al. 2005). Partitioning QTL into categories according to their mode of inheritance allowed us to compare the distribution of the mode of inheritances among QTL for the different traits in relation to the direction of their effects (increasing or decreasing) compared to the control (M82). As reflected in Fig. 2, reproductive traits (TY, BY, FN and FW) tended to show more overdominance among the increasing QTL than did the vegetative traits, $\mathrm{BX}$ and $\mathrm{PW}$. This trend was true for the number of overdominant QTL as well as for the sum of their effects relative to the sum of the recessive, additive and dominant ones. A similar trend of more heterosis among reproductive traits has been reported by others (Hua et al. 2003; Mei et al. 2003) with respect to mid-parent heterosis. When comparing increasing and decreasing QTL 

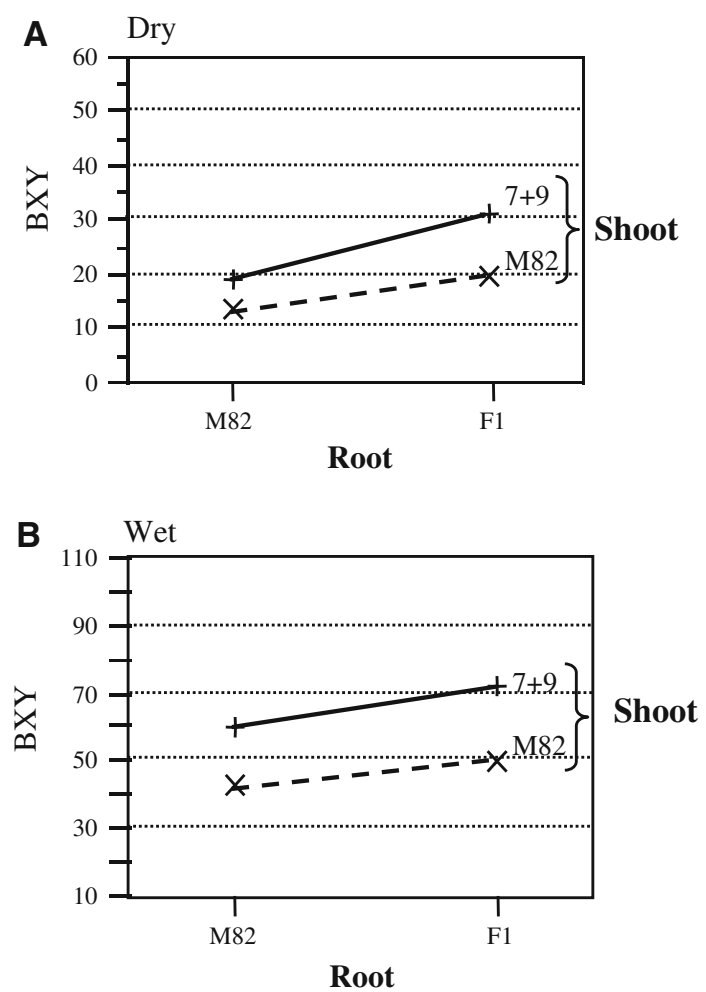

Fig. 4 Analysis of IL7 +9 shoot effect on Brix $\times$ yield $(B Y)$ under the M82 and F1 rootstocks in wet and dry fields. Two-ways ANOVA for the IL7 +9 shoot effect and the S.pennellii $\times$ M82 root effect in the wet (a) and dry (b) experiments. Each combination was tested in 20 replications under each irrigation regime

among the reproductive traits, there was a clear difference: whereas most of the increasing QTL showed dominant or overdominant mode of inheritances, with the decreasing ones, most were recessive. This observation is important from the breeding perspective; it suggests that most of the positive yield-related phenotypes represent a gain-offunction variation, while the negative QTL were mainly due to loss-of-function recessive variants. As breeders seek new sources of genetic variation, among them induced mutations, our results suggest that a variation resource that harbors mainly recessive mutations is unlikely to induce improvement in yield-related traits. However, natural wildspecies variation allows for the detection of rare dominant variants that will probably lead to better success in breeding projects.

Despite the many generations of selections for improved yield and increased fruit size in tomato, there are still reports of transgressive segregation for these traits in segregating populations of interspecific crosses (DeVicente and Tanksley 1993; Tanksley and Nelson 1996; Monforte et al. 1997). This is an indication of the existence of unused beneficial alleles in the wild parents that were lost during the process of domestication. Estimating the level of this phenomenon is important as a tool for predicting future progress in yield improvement using wild species. The number of increasing and decreasing QTL are presented in Fig. 2, and the shape of the distribution in the whole population in Fig. 1. For both TY and FW, there is a nearly symmetrical distribution of these parameters in the dry field; the number of increasing QTL for TY was eight and the number of decreasing QTL was ten. For FW there were 14 increasing QTL and 13 decreasing. In the wet field more decreasing than increasing QTL were detected for both traits, but yet there is a considerable portion of significant transgressive variation. Such results provide strong support for the unused potential of exotic variation for improving yield-related traits.
Fig. 5 Additive and nonadditive interaction between shoot and root

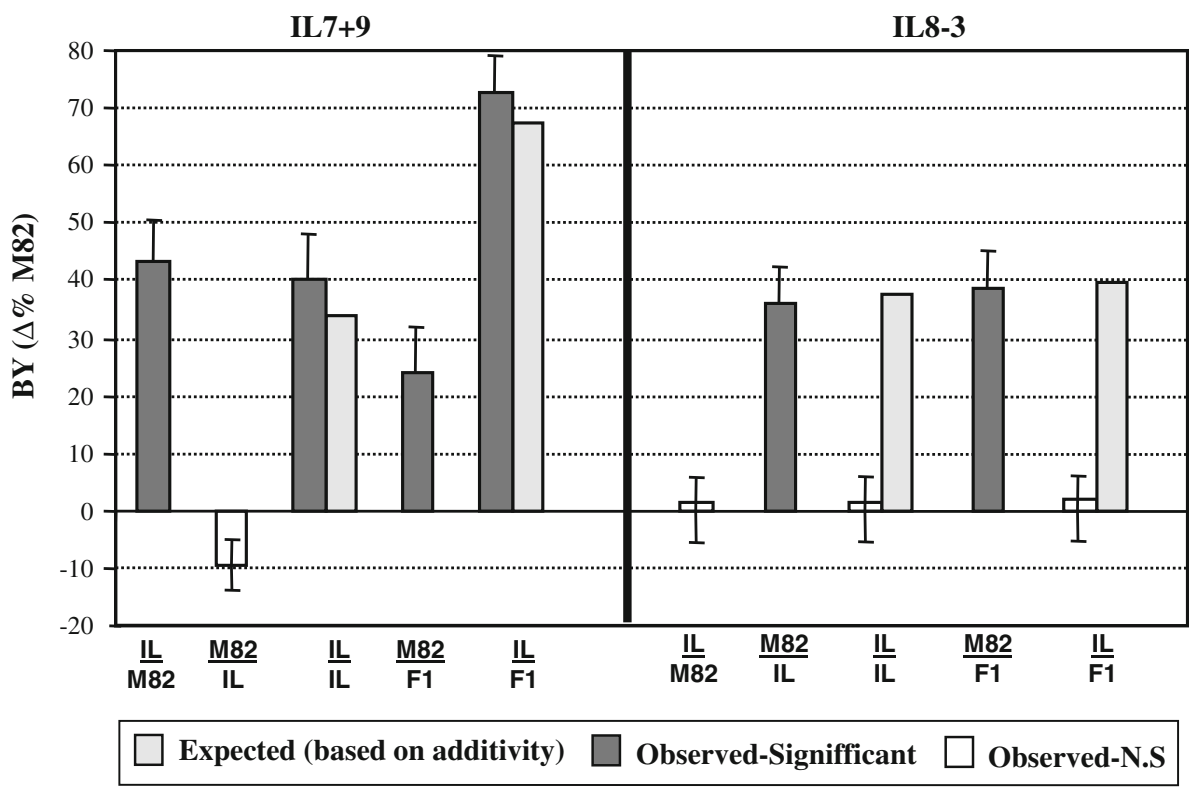


Fig. 6 Metabolite profiles in red fruits of grafting combination of IL 8-3 scion with M82 rootstock (M82:IL 8-3) and IL 8-3. Data are normalized with respect to the mean response calculated for M82 grafted and for M82 in each case. Values presented are the mean \pm SE of six replicates; values set with asterisk were determined by the $t$ test to be significantly different $(P<0.05)$

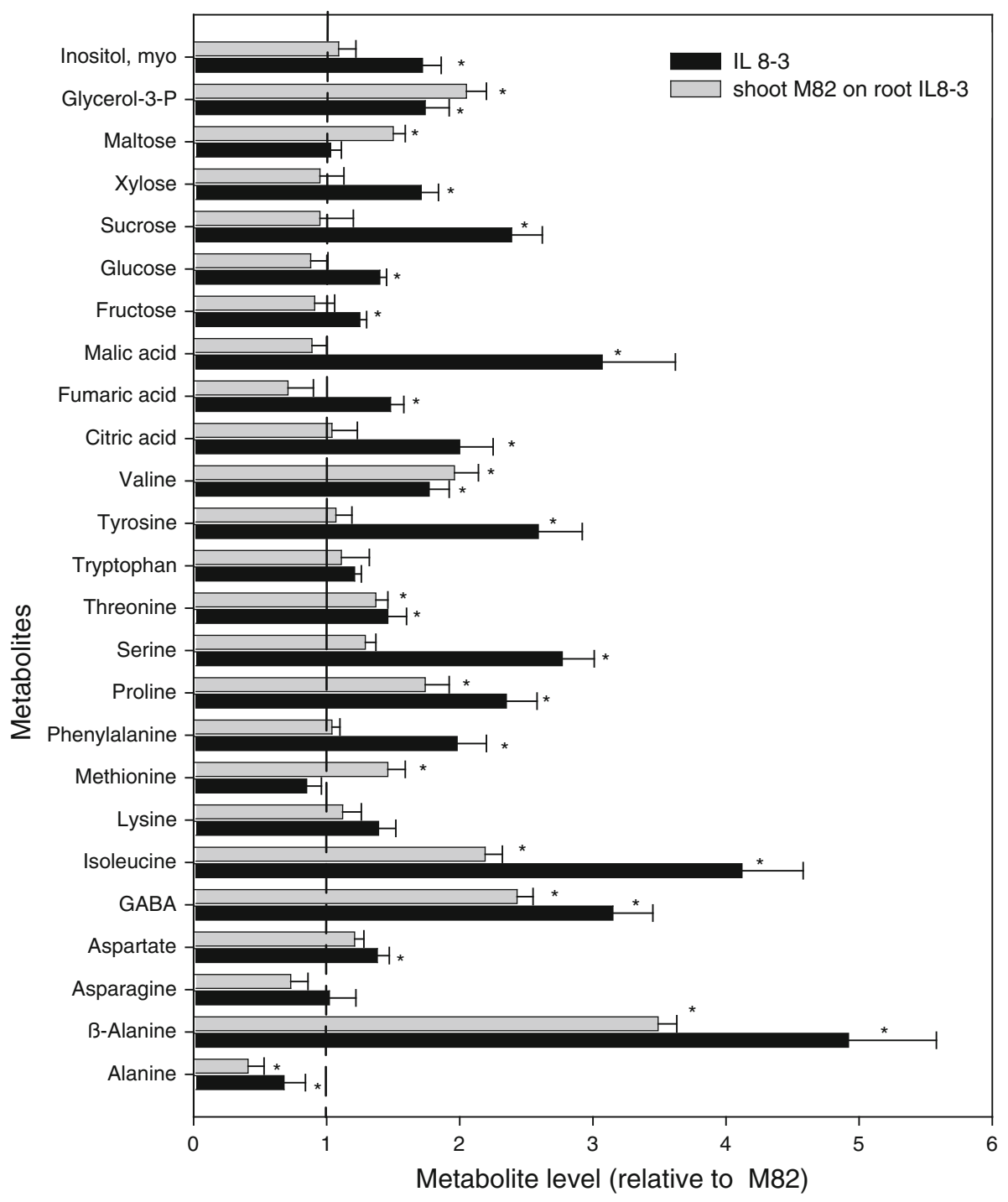

QTL across environments

Drought stress was manifested primarily in reduced development of vegetative and reproductive organs and resulted in lower values of yield-related traits (except for $\mathrm{BX}$ ). If this environmental effect was acting equally on all phenotypes, we would expect to find similar $\mathrm{CV}$ values reflecting a proportional change in the variation and mean. However, this was not the case for most of the measured traits in this study. As presented in Table 1, there was a reduction in the $\mathrm{CV}$ values (of genotype means, representing the genetic CV) for most traits (except BX and $\mathrm{FW})$. This is an indication that the drought stress had a stronger impact on the ILs with the high phenotypic values, which resulted in a larger reduction of the phenotypic values for such lines. There is a long-held notion that selection for stress tolerance generally results in reduced productivity under favorable environments (Finley and
Wilkinson 1963; Rosielle and Hambilon 1981). However, in this study, the majority of QTL that were detected were either conserved across the wet and dry or were detected only in the wet field (Fig. 2; Supplementary Table 1). Only a small number of QTL were detected as drought specific ( $\sim 15 \%$ across all traits). These findings are in partial agreement with previous QTL studies in cotton and sorghum that were performed under wet and dry conditions (Tuinstra et al. 1997; Saranga et al. 2001; Paterson et al. 2003) and additionally, perhaps, what would be anticipated from small-scale studies of genetic variance in tomato (Semel et al. 2006). Altogether, it appears that at least in the tomato IL population, yield improvements under dry conditions were achieved mainly by the action of overdominant QTL that improve productivity, rather than QTL that provide physiological drought tolerance and, hence, there was no penalty for this drought tolerance under optimal conditions. In addition to this conservation of 
detected QTL, which was also reflected in the high phenotypic correlations between dry and wet groups (Table 2c), we found that the correlations between traits were also highly conserved across the dry and wet environments. These sets of trait correlations represent a phenotypic network that is an important component in the characterization of any biological system. Such a comparison between networks across different environments, if performed using a wider range of phenotypic traits, can highlight new perspectives on organismal development. In all trials, we detected strong main factors of genotype and irrigation effects, as well as a very significant interaction between the two.

Grafting as a tool for linking between root and shoot traits and uncovering hidden variation

The approach presented here to detect associations between root or shoot effects and yield-related phenotypes is based on the reciprocal grafting concept. This approach bypasses the need for destructive morphological and/or physiological characterization of roots (Tuberosa et al. 2002) and thus enables a direct estimation of the associations between root or shoot traits and the resulting yield. While similar grafting approach was, however, recently employed in tomato to identify fruit loci controlling salt tolerance (Estañ et al. 2009), this did not implicity measure yield QTL since it only focussed on stressed conditions. It was furthermore restricted to a single harvest. However, it should be mentioned that since the root traits are not directly characterized, the conclusions are based on circumstantial evidence and do not provide an explanation for the physiological or developmental reason for the yield variation. Thus, the ability to distinguish between root- and shoot-related yield QTL, as presented here, provides a unique platform for further explorations of the physiological mode of the observed responses. Moreover, the root QTL that was identified in grafting experiments of IL8-3 represent concealed genetic variation (at least in the resolution of the IL population). In non-grafted plants, the effects of this root QTL was dominated by contrasting shoot QTL and, therefore, it could not be distinguished. By separating between these different QTL types (root and shoot) using the reciprocal grafting approach, we exposed the root QTL. As these root and shoot QTLs in IL8-3 most likely represent two independent loci, it would not be unreasonable to assume that the root QTL could be separated and detected through fine mapping experiment.

However, on a genome-wide level, the grafting approach has a clear advantage as it eliminates the need for considering epistatic or contrasting shoot effects, since all the root effect variation is analyzed under a uniform shoot background. These results also highlight the limitations associated with whole-organism phenotyping: internal physiological interactions mask some of the variation that exists and this portion of the hidden variation can only be identified by high-resolution genetics or by high-resolution phenotyping techniques such as the grafting approach.

The strength of the QTL-grafting approach extends beyond the ability to identify shoot- or root-specific QTL. We demonstrate that this approach is also useful for exploring interactions between shoot and root effects. Grafting is routinely used to study physiological aspects of root/shoot cross talk, but the direct relation between such interactions and yield, as presented here, is unique. The analysis of IL7 +9 shoot under different root backgrounds provide an example for the additive effects of shoot and root to yield production, while the IL8-3 shoot effect was shown to be strongly epistatic. Such dissection of yield QTL can improve our ability to understand the mechanism in which they work and is an important step in the utilization of such QTL in breeding programs and in further research of the underlying genetic factors. The fact that the metabolite profiles of IL8-3 in grafted and non-grafted condition also revealed that some of the control of the metabolite content of the fruit is resident in the root is highly interesting. When the metabolites, which displayed this behavior, are evaluated, two trends become apparent. First, three of the seven metabolites, $\beta$-alanine, GABA and glycerol 3-phosphate, have been widely postulated to have signaling functions in plants. Secondly, six of the seven metabolites are amino acids, which are a highly important form of translocated carbon in tomato, and indeed previous studies in this species have demonstrated that they play an important role in whole plant carbon allocation. Thus while we cannot presently define the physiological mechanism or indeed relevance of these changes, they are highly consistent with the other data reported here.

\section{Breeding implications}

The combined genetic and physiological approaches used in this study demonstrate the importance of multidimensional characterizations of QTL for the dissection of complex phenotypes such as yield. The fact that the yield analysis was performed, using the ILs, under different genetic situations (inbreds and hybrids) and under different environmental conditions (dry and wet), provided the means to determine the mode of inheritance and pattern of expression for each QTL. The further characterization of selected QTL using grafting is a step in understanding the way in which these QTL work. Localization of the effects to root or shoot, accompanied by testing specific interactions between root and shoot using grafting, can improve the ability to select for specific QTL for crop improvement and can be used as a good basis for implementation of a 
QTL pyramiding strategy to bring shoot and root-specific QTL that perform additively into the same line. Deposition of such detailed quantitative data into genomic databases such as the tomato QTL database (http://zamir.sgn.cornell. edu/Qtl/Html/home.htm) (Gur et al. 2004) enables the accumulation and organization of a wide range of phenotypes and, in so doing, creates a platform for more integrative forms of analysis. This should enable the discovery of higher levels of organization of complex systems and better utilization of such variation resources in breeding.

The methods and results presented here assisted us in addressing the question of whether it was possible to incorporate favorable wild-species QTL into genetic backgrounds that will outperform the leading varieties in the market (Gur and Zamir 2004). Using the yield-promoting ILs identified in this study, we followed a pyramiding strategy of three independent introgressions. The yield of hybrids parented by the pyramided genotypes was more than $50 \%$ higher than a control market leader variety, under both wet and dry field conditions, in six different environments. We showed that the pyramiding of independent yield-promoting segments can lead to novel varieties that reproducibly increase productivity relative to leading commercial genotypes under both normal cultivation conditions and the stress environment of drought.

Acknowledgments The Deutsche Forschungsgemeinschaft (DFG) is gratefully acknowledged for its financial support of the Trilateral project (Germany-Israel-Palestinian) "Drought Tolerant Sun-Dried Tomatoes: A novel Product Based on Heterotic Natural Biodiversity" (FE552/3-2) to SO, SS, BG, AM, TP, ARF and DZ.

Open Access This article is distributed under the terms of the Creative Commons Attribution Noncommercial License which permits any noncommercial use, distribution, and reproduction in any medium, provided the original author(s) and source are credited.

\section{References}

Ash C, Jasny BR, Malakoff DA, Sugden AM (2010) Feeding the future. Science 327:797-798

Auger DL, Gray AD, Ream TS, Kato A, Coe EH et al (2004) Nonadditive gene expression in diploid and triploid hybrids of maize. Genetics 169:389-397

Champoux M, Wang G, Sarkarung S, Mackill D, Otoole J et al (1995) Locating genes associated with root morphology and drought avoidance in rice via linkage to molecular markers. Theor Appl Genet 90:969-981

DeVicente MC, Tanksley SD (1993) QTL analysis of transgressive segregation in an interspecific tomato cross. Genetics 134:585-596

Diaz-Ruiz R, Torres AM, Satovic Z, Gutierrez MV, Cubero JI et al (2010) Validation of QTLs for Orobanche crenata resistance in faba bean (Vicia faba L.) across environments and generations. Theor Appl Genet 120:909-919

Dunnet CW (1955) A multiple comparison procedure for comparing several treatments with a control. J Am Stat Assoc 50: $1096-1121$
Eshed Y, ZAMIR D (1995) An introgression line population of Lycopersicon pennellii in the cultivated tomato enables the identification and fine mapping of yield-associated QTL. Genetics 141:1147-1162

Estañ MT, Martinez-Rodriguez MM, Perez-Alfocea F, Flowers TJ, Bolarin MC (2005) Grafting raises the salt tolerance of tomato through limiting the transport of sodium and chloride to the shoot. J Exp Bot 56:703-712

Estañ MT, Villalta I, Bolarín MC, Carbonell EA, Asins MJ (2009) Identification of fruit yield loci controlling the salt tolerance conferred by solanum rootstocks. Theor Appl Genet 118:305-312

Fedoroff NV, Battisti RN, Beachy RN, Cooper PJM, Fischhof CN et al (2010) Radically rethinking agriculture for the 21st century. Science 327:833-834

Fernie AR, Trethewey RN, Krotzy AJ, Willmitzer L (2004) Metabolite profiling: from diagnostics to systems biology. Nat Rev Mol Cell Biol 5:763-769

Finley KW, Wilkinson G (1963) The analysis of adaptation in a plantbreeding program. Aust J Agric Res 14:742-754

Guingo E, Hebert Y, Charcosset A (1998) Genetic analysis of root traits in maize. Agronomie 18:225-235

Gur A, Zamir D (2004) Unused natural variation can lift yield barriers in plant breeding. PLoS Biol 2:E245

Gur A, Semel Y, Cahaner A, Zamir D (2004) Real-time QTL of complex phenotypes in tomato interspecific introgression lines. Trends Plant Sci 9:107-109

Heaton EA, Flavell RB, Mascia PN, Thomas SR, Doehleman FG, Long SP (2008) Herbaceous energy crop development: recent progress and future prospects. Curr Opin Biotech 19:202-209

Hoekenga OA, Maron LG, Pineros MA, Cancado GMA, Shaff J et al (2006) AtALMT1, which encodes a malate transporter, is identified as one of several genes critical for aluminium tolerance in Arabidopsis. Proc Natl Acad Sci USA 103:97389743

Hoisington D, Khairallah M, Reeves T, Ribaut JM, Skovmand B et al (1999) Plant genetic resources: what can they contribute toward increased crop productivity? Proc Natl Acad Sci USA 96:59375943

Hua J, Xing Y, Wu W, Xu C, Sun X et al (2003) Single-locus heterotic effects and dominance by dominance interactions can adequately explain the genetic basis of heterosis in an elite rice hybrid. Proc Natl Acad Sci USA 100:2574-2579

Janhnke S, Menzel MI, Van Dusschoten D, Roeb GW, Buhler J et al (2009) Combined MRI-PET dissects dynamic changes in plant structures and functions. Plant J 69:534-544

Kopka J, Schauer N, Krueger S, Birkemeyer C, Usadel B et al (2005) GMD@CSB.DB: the golm metabolome database. Bioinformatics 21:1635-1638

Lebreton C, Lazicjancic V, Steed A, Pekic S, Quarrie S (1995) Identification of QTL for drought responses in maize and their use in testing causal relationships between traits. J Exp Bot $46: 853-865$

Li ZK, Luo LJ, Mei HW, Wang DL, Shu QY et al (2001) Overdominant epistatic loci are the primary genetic basis of inbreeding depression and heterosis in rice. I. Biomass and grain yield. Genetics 158:1737-1753

Lisec J, Schauer N, Kopka J, Willmitzer L, Fernie AR (2006) Gas chromatography mass spectrometry-based metabolite profiling in plants. Nat Protoc 1:387-396

Lisec J, Steinfath M, Meyer RC, Selbig J, Melchinger AE, Willmitzer L, Altmann T (2009) Identification of heterotic metabolite QTL in Arabidopsis thaliana RIL and IL populations. Plant J 59: 777-788

Mansur L, Lark K, Kross H, Oliveira A (1993) Interval mapping of quantitative trait loci for reproductive, morphological, and seed traits of soybean (glycine-max 1). Theor Appl Genet 86:907-913 
Mei HW, Luo LJ, Ying CS, Wang YP, Yu XQ et al (2003) Gene actions of QTLs affecting several agronomic traits resolved in a recombinant inbred rice population and two testcross populations. Theor Appl Genet 107:89-101

Monforte AJ, Asins MJ, Carbonell EA (1997) Salt tolerance in Lycopersicon species. 5. Does genetic variability at quantitative trait loci affect their analysis? Theor Appl Genet 95:284-293

Pan Q, Liu YS, Budai-Hadrian O, Sela M, Carmel-Goren L et al (2000) Comparative genetics of nucleotide binding site-leucine rich repeat resistance gene homologues in the genomes of two dicotyledons: tomato and arabidopsis. Genetics 155:309-322

Paterson AH, Saranga Y, Menz M, Jiang CX, Wright RJ (2003) QTL analysis of genotype $\times$ environment interactions affecting cotton fiber quality. Theor Appl Genet 106:384-396

Peng SB, Huang JL, Sheehy JE, Laza RC, Visperas RM, Zhong XH, Centeno GS, Khush GS, Cassman KG (2004) Rice yields decline with higher night temperature from global warming. Proc Natl Acad Sci USA 101:9971-9975

Ray J, Yu L, Mccouch S, Champoux M, Wang G et al (1996) Mapping quantitative trait loci associated with root penetration ability in rice (Oryza sativa L.). Theor Appl Genet 92:627-636

Rosegrant MW, Cline SA (2003) Global food security: challenges and policies. Science 302:1917-1919

Rosielle AA, Hambilon J (1981) Theoretical aspects of selection for yield in stress and non-stress environments. Crop Sci 21:943-946

Saranga Y, Menz M, Jiang CX, Wright RJ, Yakir D et al (2001) Genomic dissection of genotype $\mathrm{x}$ environment interactions conferring adaptation of cotton to arid conditions. Genome Res 11:1988-1995

Schauer N, Semel Y, Roessner U, Gur A, Balbo I, Carrari F, Pleban T, Perez-Melis A, Bruedigam C, Kopka J, Willmitzer L, Zamir D, Fernie AR (2006) Comprehensive metabolic profiling and phenotyping of interspecific introgression lines for tomato improvement. Nat Biotechnol 24:447-454

Schauer N, Semel Y, Balbo I, Steinfath M, Repsilber D, Selbig J, Pleban T, Zamir D, Fernie AR (2008) Mode of inheritance of primary metabolic traits in tomato. Plant Cell 20:509-523

Semel Y, Nissenbaum J, Menda N, Zinder M, Krieger U et al (2006) Overdominant quantitative trait loci for yield and fitness in tomato. Proc Natl Acad Sci USA 103:12981-12986

Semel Y, Schauer Y, Roessner U, Zamir D, Fernie AR (2007) Metabolite analysis for the comparison of irrigated and non- irrigated field grown tomato of varying genotype. Metabolomics 3:289-295

Specht J, Chase K, Macrander M, Graef G, Chung J et al (2001) Soybean response to water: a QTL analysis of drought tolerance. Crop Sci 41:493-509

Svistoonoff S, Creff A, Reymond M, Siqoillot-Claude C, Ricaud L, Blanchet A, Nussaume T, Desnos T (2007) Root tip contact with low-phosphate media reprograms plant root architecture. Nat Gen 39:792-796

Swarbrick PJ, Huang K, Liu G, Slate J, Press MC, Scholes JD (2008) Global patterns of gene expression in rice cultivars undergoing a susceptible or resistant interaction with the parasitic plant Striga hermonthica. New Phytol 179:515-529

Tanksley S, Nelson J (1996) Advanced backcross QTL analysis: a method for the simultaneous discovery and transfer of valuable QTLs from unadapted germplasm into elite breeding lines. Theor Appl Genet 92:191-203

Teulat B, This D, Khairallah M, Borries C, Ragot C et al (1998) Several QTLs involved in osmotic adjustment trait variation in barley (Hordeum vulgare L.). Theor Appl Genet 96:688-698

Tuberosa R, Sanguineti MC, Landi P, Giuliani MM, Salvi S et al (2002) Identification of QTLs for root characteristics in maize grown in hydroponics and analysis of their overlap with QTLs for grain yield in the field at two water regimes. Plant Mol Biol 48:697-712

Tuinstra M, Grote E, Goldsbrough P, Ejeta G (1997) Genetic analysis of post-flowering drought tolerance and components of grain development in Sorghum bicolor (L.) Moench. Mol Breed 3:439-448

Van der Merwe MJ, Osorio S, Moritz T, Nunes-Nesi A, Fernie AR (2009) Decreased mitochondrial activities of malate dehydrogenase and fumarase in tomato lead to altered root growth and architecture via diverse mechanisms. Plant Physiol 149:653-669

Vuylsteke M, Van Eeuwijk F, Van Hummelen P, Kuiper M, Zabeau $M$ (2005) Genetic analysis of variation in gene expression in Arabidopsis thaliana. Genetics 171:1267-1275

Xiao J, Li J, Yuan L, Tanksley SD (1995) Dominance is the major genetic basis of heterosis in rice as revealed by QTL analysis using molecular markers. Genetics 140:745-754

Yadav R, Courtois B, Huang N, McLaren G (1997) Mapping genes controlling root morphology and root distribution in a doubledhaploid population of rice. Theor Appl Genet 94:619-632 